\title{
Effect of Tranexamic Acid on Transfusion Requirement in Dual Antiplatelet-Treated Anemic Patients Undergoing Off-Pump Coronary Artery Bypass Graft Surgery - A Randomized Controlled Study -
}

So Woon Ahn, MD; Jae Kwang Shim, MD, PhD; Young Nam Youn, MD, PhD; Jong Wook Song, MD; So Young Yang, MD; Sung Chan Chung, MD; Young Lan Kwak, MD, PhD

\begin{abstract}
Background: Anemia is not rare in patients presenting for coronary artery bypass graft surgery (CABG) and as these patients are frequently on dual antiplatelet therapy (DAPT), the coexisting conditions could potentially increase the risk of bleeding and transfusion. The aim of this study was to evaluate the effect of tranexamic acid (TA) on blood loss and transfusion in preoperatively anemic patients who continued DAPT until within 5 days of off-pump CABG (OPCAB).
\end{abstract}

\begin{abstract}
Methods and Results: Seventy-six anemic patients were randomized into 2 groups: TA group receiving TA (1 g bolus followed by infusion at $200 \mathrm{mg} / \mathrm{h}$ ) and a Control group receiving the same volume of saline. The amount of blood loss and transfusion requirement during, and at 4 and $24 \mathrm{~h}$ after the operation were assessed. Patients' characteristics and operative data were similar between the groups. During the perioperative period, which combined the intraoperative and postoperative $24 \mathrm{~h}$ data, the TA group received significantly smaller amounts of packed red blood cells and fresh frozen plasma. Total amount of perioperative blood loss was similar between the groups, although the blood loss during the postoperative $4 \mathrm{~h}$ was significantly less in the TA group.
\end{abstract}

Conclusions: TA infusion could reduce the amount of transfusion during the perioperative period in patients with preoperative anemia who continue DAPT until within 5 days of OPCAB. (Circ J 2012; 76: 96-101)

Key Words: Anemia; Dual antiplatelet therapy; Off-pump coronary artery bypass; Tranexamic acid

$\mathbf{I}$ ncreased bleeding and subsequent transfusion of allogeneic blood products are undoubtedly associated with adverse outcome in cardiac surgical patients. ${ }^{1}$ Among many risk factors, preoperative anemia is one of the strongest predictors of transfusion. ${ }^{2}$ In coronary patients presenting for coronary artery bypass graft surgery $(\mathrm{CABG})$, mild preoperative anemia is not rare, but surgery often cannot be delayed, especially in patients with acute coronary syndrome. ${ }^{3}$ Moreover, the need for dual antiplatelet therapy (DAPT) consisting of aspirin and clopidogrel further complicates the perioperative course of these patients in terms of blood loss and transfusion requirement. ${ }^{4-6}$

In order to maximize the ischemic benefit and minimize the bleeding risk in patients receiving DAPT until shortly before surgery, off-pump CABG (OPCAB) has been proposed as an alternative technique of surgical revascularization..$^{7,8}$ However, patients with preoperative anemia have a reduced red blood cell reserve that is likely to be depleted by operative intervention, even without the use of cardiopulmonary bypass (CPB). In addition, anemia per se has been demonstrated to be associated with reversible platelet dysfunction. ${ }^{9}$ Therefore, coexistence of anemia and continued DAPT may potentially result in an increased risk of bleeding and transfusion requirement mandating the need for an effective blood conservation strategy.

Tranexamic acid (TA) is a synthetic antifibrinolytic agent that binds to the lysine-binding sites of plasminogen. ${ }^{10}$ TA can reduce postoperative blood loss and transfusion requirement in cardiac surgery with and without CPB. ${ }^{11}$ TA has improved platelet function in chronic renal failure patients ${ }^{12}$ and reduced postoperative blood loss in patients treated with antiplatelet therapy undergoing CABG. ${ }^{13,14}$ Also, a recent study demonstrated that TA actually increased platelet aggregation in patients treated with aspirin and clopidogrel undergoing CABG. ${ }^{14}$ Therefore, coronary patients with preoperative anemia who are

Received July 27, 2011; accepted September 15, 2011; released online October 28, 2011 Time for primary review: 26 days

Department of Anesthesiology and Pain Medicine, Kwandong University College of Medicine, Goyang (S.W.A.); Department of Anesthesiology and Pain Medicine, Seoul (J.K.S., J.W.S., S.Y.Y., S.C.C., Y.L.K.); Anesthesia and Pain Research Institute, Seoul (J.K.S., Y.L.K.); Department of Cardiothoracic Surgery, Seoul (Y.N.Y.); and Severance Biomedical Science Institute, Yonsei University College of Medicine, Seoul (Y.L.K.), Korea

Mailing address: Young Lan Kwak, MD, PhD, Department of Anesthesiology and Pain Medicine and Anesthesia and Pain Research Institute, Yonsei University Health System, 250 Seongsanno, Seodaemun-gu, Seoul, 120-752, South Korea. E-mail: ylkwak@yuhs.ac

ISSN-1346-9843 doi:10.1253/circj.CJ-11-0811

All rights are reserved to the Japanese Circulation Society. For permissions, please e-mail: cj@j-circ.or.jp 


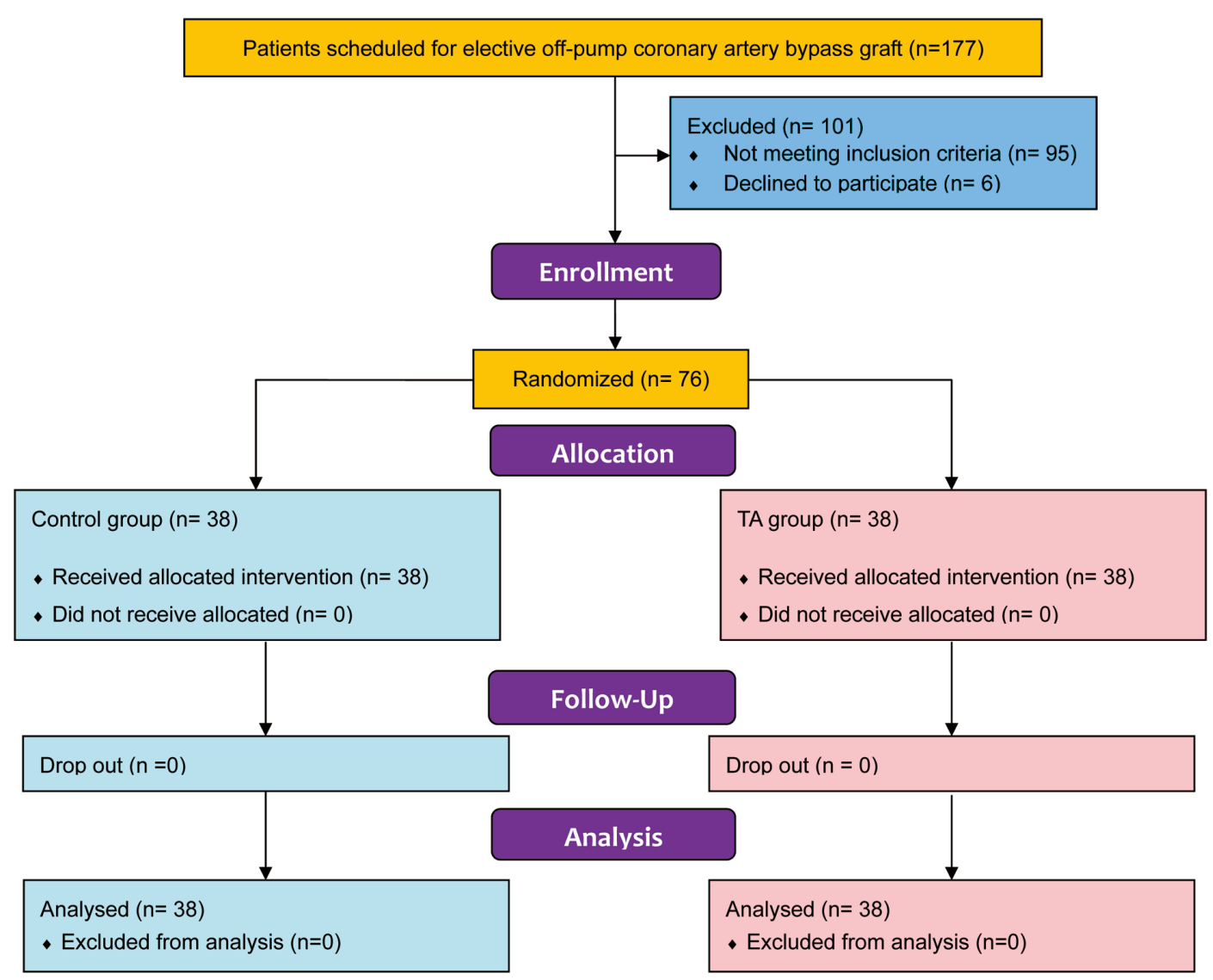

Figure. Flow chart of study design.

on continued DAPT until shortly before OPCAB could benefit from TA infusion in terms of blood conservation, yet no comprehensive data exist in that regard.

The aim of this randomized, double-blinded, placebo-controlled study was to evaluate the effect of TA on transfusion requirement and blood loss in preoperatively anemic patients who have been administered DAPT until within 5 days of OPCAB.

\section{Methods}

After obtaining the approval of the institutional ethics board and informed written consent from all patients, 76 preoperatively anemic patients (hemoglobin $[\mathrm{Hb}] \leq 130 \mathrm{~g} / \mathrm{L}$ for males, $\leq 120 \mathrm{~g} / \mathrm{L}$ for females) treated with aspirin and clopidogrel until within 5 days of OPCAB were randomized into 2 groups using the envelope method with random numbers. Patients in the TA group $(n=38)$ received $1 \mathrm{~g}$ of TA (Shinpoong, Seoul, Korea) for $20 \mathrm{~min}$ before skin incision with subsequent continuous infusion at $200 \mathrm{mg} / \mathrm{h}$ during the operation. ${ }^{15}$ Patients in the Control group $(n=38)$ received the equivalent amount of saline solution at the same infusion rate. The infusion syringe was prepared by an anesthetic nurse who was not involved in the study. Both the anesthesiologists and cardiac surgeons in the operating room and intensive care unit (ICU) were blinded to the randomization result by the use of unmarked identical syringes for TA and saline administration. Patients with impaired renal function (serum creatinine $[\mathrm{sCr}]>20 \mathrm{mg} / \mathrm{L}$ ), hepatic dysfunc- tion, neurologic dysfunction or hematologic disorders were excluded.

The same, previously described anesthetic technique was used for all patients. ${ }^{16}$ Systemic heparinization during anastomosis was achieved with $100 \mathrm{U} / \mathrm{kg}$ of porcine heparin to reach a target activated clotting time (ACT) $>250 \mathrm{~s}$, which was maintained with additional doses of heparin as necessary. ACT was checked at 30-min intervals until the completion of anastomosis. Adequate graft flow was confirmed and the heart was returned to its natural position by the surgeon. Then, heparin was neutralized with protamine sulfate $(0.5 \mathrm{mg} / 100 \mathrm{U}$ of heparin). The amount of heparin injected and protamine for reversal of heparinization during operation, baseline ACT value before anastomosis, highest ACT value during anastomosis, and ACT value after protamine reversal were recorded. The graft was exposed and stabilized as described previously. ${ }^{16}$ Preoperative autologous blood donation was not performed in any patient of either group. A cell salvage device (Cell saver ${ }^{\circledR}$, Haemonetics Corp, MA, USA) was used during the operation in all patients, and salvaged blood was reinfused to the patient before the end of the operation. All patients were transferred to ICU after operation.

Allogeneic packed red blood cells (pRBC) were transfused when the $\mathrm{Hb}$ level was $<85 \mathrm{~g} / \mathrm{L}$ throughout the study period. Fresh frozen plasma (FFP) was transfused when the postoperative international normalized ratio was $>1.5$ with excessive bleeding $>200 \mathrm{ml} / \mathrm{h}$ for 2 consecutive hours. The criteria for transfusion of platelet concentrate were postoperative plate- 


\begin{tabular}{lccc|}
\hline Table 1. Patients' Characteristics & & & \\
& Control $(\mathbf{n}=\mathbf{3 8})$ & TA $(\mathbf{n}=\mathbf{3 8})$ & P value \\
Age (years) & $67(7)$ & $69(7)$ & 0.249 \\
Sex (M/F) & $18 / 20$ & $23 / 15$ & 0.250 \\
BSA (m²) & $1.6(0.2)$ & $1.6(0.2)$ & 0.984 \\
EuroSCORE & $4.5(2.3)$ & $4.7(2.2)$ & 0.578 \\
Ejection fraction (\%) & $64(10)$ & $60(13)$ & 0.109 \\
Diabetes mellitus & 19 & 22 & 0.490 \\
Hypertension & 28 & 34 & 0.076 \\
Peripheral obstructive disease & 12 & 7 & 0.185 \\
Left main coronary disease & 7 & 13 & 0.118 \\
Triple vessel disease & 36 & 36 & $>0.999$ \\
Prior MI & 6 & 4 & 0.497 \\
Recent MI (<1 month) & 3 & 4 & $>0.999$ \\
Fibrinogen (mg/dl) & $343.9(108.5)$ & $347.6(100.6)$ & 0.899 \\
Time of aspirin and clopidogrel discontinuation & $2[1-3]$ & $2[1-2]$ & 0.185 \\
before surgery (days) & & & \\
\hline
\end{tabular}

Values are mean (SD), median [interquartile range] or number of patients.

TA, tranexamic acid; BSA, body surface area; MI, myocardial infarction.

\begin{tabular}{|lccc|}
\hline Table 2. Operative Data & & & \\
& $\begin{array}{c}\text { Control } \\
(\mathbf{n = 3 8})\end{array}$ & $\begin{array}{c}\text { TA } \\
(\mathbf{n}=\mathbf{3 8})\end{array}$ & P value \\
Operating time (min) & $246(51)$ & $250(47)$ & 0.747 \\
No. of grafts & $3.1(0.6)$ & $3.1(0.6)$ & $>0.999$ \\
Heparin (IU) & $7,044(2,716)$ & $7,781(2,272)$ & 0.84 \\
Protamine (mg) & $33(12)$ & $38(13)$ & 0.263 \\
Baseline ACT (s) & $140(14)$ & $150(22)$ & 0.114 \\
Highest ACT (s) & $390(76)$ & $368(77)$ & 0.396 \\
Reversed ACT (s) & $154(22)$ & $149(16)$ & 0.435 \\
Crystalloid (ml) & $2,421(726)$ & $2,275(684)$ & 0.375 \\
Colloid (ml) & $1,131(272)$ & $1,120(309)$ & 0.874 \\
Urine output (ml) & $692(41)$ & $726(391)$ & 0.715 \\
\hline
\end{tabular}

Values are mean (SD).

TA, tranexamic acid; ACT, activated clotting time; Baseline ACT, initial level of ACT during operative period; Highest ACT, highest level of ACT during operative period; Reversed ACT, ACT after reversal with protamine.

let count $<50 \times 10^{9} / \mathrm{L}$ with excessive bleeding $>200 \mathrm{ml} / \mathrm{h}$ for 2 consecutive hours. Surgical re-exploration was indicated when chest tube drainage was $>200 \mathrm{ml} / \mathrm{h}$ for 4 consecutive hours or $>400 \mathrm{ml}$ during the first hour despite normalized ACT and global coagulation status. Anesthesiologists and cardiac surgeons involved in the primary care of the patients during the study period were all blinded to the patients' group allocations.

$\mathrm{Hb}$ levels and platelet counts were measured preoperatively, at the end of operation, and $24 \mathrm{~h}$ after operation. The lowest $\mathrm{Hb}$ level during the postoperative period was also recorded. Prothrombin time (PT), and activated partial thromboplastin time were measured preoperatively and $24 \mathrm{~h}$ after operation. During the intraoperative period, fluid balance, amount of pRBC transfusion, and number of patients transfused were recorded. Intraoperative blood loss was recorded as the amount of reinfused salvaged blood by the cell salvage device. Postoperative blood loss was recorded as the volume of chest tube drainage measured at $4 \mathrm{~h}$ and $24 \mathrm{~h}$ after operation, and the drained blood was not reinfused. The amount of transfused pRBC, FFP, and platelet concentrate during $4 \mathrm{~h}$ and $24 \mathrm{~h}$ after operation and numbers of patients requiring $\mathrm{pRBC}$ transfusion during $4 \mathrm{~h}$ and $24 \mathrm{~h}$ after operation were recorded. During hospitalization, possible thromboembolic complications as a result of TA treatment, including myocardial infarction (MI, increase in Tn-T $>0.8 \mathrm{ng} / \mathrm{ml}$ and/or development of pathologic Q wave on ECG) ${ }^{17}$ acute renal insufficiency ( $\mathrm{sCr} \geq 3 \mathrm{mg} / \mathrm{L}$ or $50-200 \%$ from baseline using modified RIFLE classification), ${ }^{18}$ major neurologic dysfunction (transient ischemic attack or stroke), pulmonary embolism, and deep vein thrombosis were recorded.

The primary endpoint of this study was to compare the perioperative (combined period of intraoperative and postoperative $24 \mathrm{~h}$ ) transfusion requirement between the groups. The secondary endpoint of this study was to compare the amount of perioperative blood loss between the groups.

Statistical analyses were performed with SPSS 15.0 (SPSS Inc, Chicago, IL, USA). A difference of 1 unit transfusion of pRBC between the groups was taken as clinically significant reduction. Based on the OPCAB results of our hospital in patients who continued clopidogrel until within 5 days of surgery, the standard deviation in the amount of perioperative pRBC transfusion was 1.5 units. ${ }^{16}$ This calculation generated an estimate of 36 patients in each group with $80 \%$ power and an alpha level of 0.05 . All data are expressed as the number of patients (percentage) or the mean \pm SD. The normality of distribution was assessed with a q-q plot and the Shapiro-Wilk test. Data between groups were compared by $\chi^{2}$ test, Fisher's exact test, or independent t-test with post hoc comparison using the Bonferroni test as appropriate. A P value $<0.05$ was considered significant.

\section{Results}

OPCAB was successfully performed in all patients without requiring emergency conversion to an on-pump procedure. Thus, data for all 76 patients were analyzed. None of the patients underwent reoperation because of bleeding (Figure).

Patients' characteristics and the preoperative fibrinogen level were all statistically not different between the groups (Table 1). Operative data, including the number of grafts performed, were also similar between the groups (Table 2).

The amounts of perioperative blood loss and transfusion requirement are listed in Table 3. Overall, during the perioperative period (which combined the intraoperative and $24 \mathrm{~h}$ 


\begin{tabular}{|c|c|c|c|c|}
\hline & Introperative & $\begin{array}{c}\text { Postoperative } \\
4 \mathrm{~h}\end{array}$ & $\begin{array}{c}\text { Postoperative } \\
24 \mathrm{~h}\end{array}$ & Total \\
\hline \multicolumn{5}{|c|}{ Blood loss (ml) } \\
\hline Control & $221(147)$ & $237(158)$ & 729 (449) & $944 \pm 482$ \\
\hline TA & $236(196)$ & $167(134)^{\star}$ & 751 (489) & $986 \pm 520$ \\
\hline$P$ value & 0.718 & 0.041 & 0.832 & 0.720 \\
\hline \multicolumn{5}{|c|}{ Amount of pRBC (units) } \\
\hline Control & $1.0 \pm 1.0$ & $0.2 \pm 0.4$ & $0.4 \pm 0.8$ & $1.4 \pm 1.2$ \\
\hline TA & $0.5 \pm 0.7^{\star}$ & $0.0 \pm 0.2$ & $0.2 \pm 0.6$ & $0.8 \pm 0.8^{*}$ \\
\hline$P$ value & 0.016 & 0.061 & 0.340 & 0.010 \\
\hline \multicolumn{5}{|c|}{ Patients requiring pRBC (\%) } \\
\hline Control & $24(71)$ & $6(16)$ & $8(21)$ & $27(71)$ \\
\hline TA & $16(42)$ & $1(3)$ & $6(16)$ & $20(53)$ \\
\hline$P$ value & 0.066 & 0.108 & 0.554 & 0.098 \\
\hline \multicolumn{5}{|c|}{ Amount of FFP (units) } \\
\hline Control & $0.05 \pm 0.32$ & & $0.34 \pm 0.97$ & $0.39 \pm 1.00$ \\
\hline TA & 0 & & $0.05 \pm 0.23$ & $0.05 \pm 0.23$ \\
\hline$P$ value & 0.321 & & 0.076 & $0.043^{*}$ \\
\hline \multicolumn{5}{|c|}{ Patients requiring FFP (\%) } \\
\hline Control & $1(3)$ & $0(0)$ & $4(11)$ & $5(13)$ \\
\hline TA & $0(0)$ & $0(0)$ & $2(5)$ & $2(5)$ \\
\hline $\mathrm{P}$ value & $>0.999$ & $>0.999$ & 0.674 & 0.430 \\
\hline
\end{tabular}

Values are mean (SD) or number of patients.

${ }^{*} \mathrm{P}<0.05$ compared with Control group.

Total, combined data of intraoperative and postoperative $24 \mathrm{~h}$; TA, tranexamic acid; pRBC, packed red blood cells; FFP, fresh frozen plasma.

postoperative period), patients in the TA group received a significantly smaller amount of pRBC transfusion, although the amount of blood loss was similar between the groups. Also, the number of patients requiring $\mathrm{pRBC}$ transfusion during the perioperative period tended to be less in the TA group (20 vs. $27, \mathrm{P}=0.098$ ). In detail, during the operation, patients in the TA group received significantly smaller $\mathrm{pRBC}$ transfusion. Also, fewer patients required $\mathrm{pRBC}$ transfusion in the TA group, without statistical significance $(\mathrm{P}=0.066)$. For the first $4 \mathrm{~h}$ after operation, the TA group lost a significantly smaller amount of blood and required less pRBC transfusion. The amount of FFP transfusion during the perioperative period was significantly less in the TA group. None of the patients was transfused with platelet concentrate during the study period.

Baseline and postoperative hematologic variables were all comparable between the groups. The lowest $\mathrm{Hb}$ level during the perioperative period was $76 \pm 9 \mathrm{~g} / \mathrm{L}$ in the Control group and $75 \pm 9 \mathrm{~g} / \mathrm{L}$ in TA group $(\mathrm{P}=0.823)$ (Table 4$)$.

The incidence of MI ( 0 vs. $1, \mathrm{P}=0.471)$ and of renal insufficiency ( 5 vs. $5, \mathrm{P}>0.999$ ) was similar between the groups. There were no reports of stroke or other thromboembolic complications in either group.

\section{Discussion}

In this prospective randomized study, we observed significantly smaller amounts of pRBC and FFP transfusion in the TA group during the perioperative study period among this cohort of patients with preoperative anemia who continued DAPT until within 5 days of OPCAB, although the differences in the total amount of blood loss and number of patients requiring $\mathrm{pRBC}$ transfusion did not reach statistical significance between the groups.

Platelets play a pivotal role in hemostasis, and platelet dys-

\begin{tabular}{|lccc|}
\hline \multicolumn{4}{|c|}{ Table 4. Hematologic Data } \\
Preoperative & $\begin{array}{c}\text { End of } \\
\text { operation }\end{array}$ & POD 1 \\
Hemoglobin (g/L) & & & \\
Control & $108(11)$ & $87(11)$ & $89(9)$ \\
TA & $109(9)$ & $84(7)$ & $88(10)$ \\
P value & 0.913 & 0.327 & 0.823 \\
Platelet count (109/L) & & & \\
Control & $274(90)$ & $169(72)$ & $162(65)$ \\
TA & $270(86)$ & $189(71)$ & $179(63)$ \\
P value & 0.857 & 0.231 & 0.260 \\
PT (s) & & & \\
Control & $11.0(2.0)$ & & $12.2(1.1)$ \\
TA & $11.0(0.8)$ & & $12.7(1.3)$ \\
P value & 0.960 & & 0.078 \\
aPTT (s) & & & \\
Control & $40.1(19.6)$ & & $32.1(7.3)$ \\
TA & $34.1(11.5)$ & & $33.8(10.6)$ \\
P value & 0.113 & & 0.422 \\
\hline
\end{tabular}

Values are mean (SD).

POD, postoperative day; TA, tranexamic acid; PT, prothrombin time; aPTT, activated partial thromboplastin time.

function is regarded as a major pathophysiologic cause of nonsurgical postoperative bleeding. ${ }^{19}$ In cardiac surgery using $\mathrm{CPB}$, it is the bypass that mainly contributes to the decrease in platelet number and function through hemodilution, adhesion, activation, and mechanical destruction. ${ }^{20}$ Not surprisingly, a considerable number of coronary patients presenting for $\mathrm{CABG}$ are at high risk of bleeding and hemorrhagic complications if they are receiving DAPT consisting of aspirin and 
clopidogrel, and such patients are recommended to discontinue the drugs 5 days prior to surgery. ${ }^{21}$ However, an increasing number of studies warn of the adverse consequences of discontinuing these agents, especially in patients with previous stent implantation or acute coronary syndrome. ${ }^{22}$ Altogether, the recent literature on antiplatelet agents implies that there may be an ischemic or even a mortality benefit with some degree of platelet inhibition at the time of CABG, despite a possible risk of excessive bleeding. ${ }^{23}$ In the context of maximizing the ischemic benefit while minimizing the bleeding and transfusion risk conveyed by DAPT, OPCAB has been proposed as an alternative surgical revascularization technique. ${ }^{8}$

Transfusion of allogeneic blood products carries risks far beyond the risk of disease transmission affecting the patient's outcome after cardiac surgery. ${ }^{1}$ Despite efforts to reduce allogeneic blood transfusion, blood transfusion is still common in patients undergoing cardiac surgery, including OPCAB. Among the many risk factors of transfusion, preoperative anemia is not uncommon in patients undergoing CABG partly because of preoperative percutaneous coronary angiography or interventions. ${ }^{24}$ Mild preoperative anemia (Hct $<35 \%$ ) has been demonstrated to be an independent risk factor of transfusion in patients undergoing OPCAB. ${ }^{2}$ Furthermore, a reduced Hct produces a reversible platelet dysfunction manifested by an increase in bleeding time and blood loss at the bleeding site. ${ }^{9}$ In most cases, however, CABG is usually not delayed based on the presence of mild preoperative anemia and these patients are frequently on DAPT. Thus, for preoperatively anemic patients who are receiving DAPT until shortly before $\mathrm{CABG}$, a strategy to reduce perioperative blood loss and transfusion is essential.

Plasmin has been demonstrated to induce platelet dysfunction by activating the complement cascade, and inducing proteolytic degradation and redistribution of platelet glycoprotein receptors. ${ }^{25}$ TA reduces the plasma concentration of plasmin by blocking the lysine-binding sites of plasminogen, thus blocking the interaction with specific lysine residues of fibrin and hindering the conversion of plasminogen to plasmin. ${ }^{10} \mathrm{TA}$ infusion has already been demonstrated to reduce postoperative blood loss and transfusion requirements in various cardiac surgeries, including OPCAB. ${ }^{11}$ Indeed, although the efficacy of TA on CPB-related platelet dysfunction was less than that of aprotinin, TA partially reversed platelet aggregation dysfunction associated with antiplatelet therapy in an in vitro analysis. ${ }^{14}$ Still, controversial results of TA had been reported in clinical studies of on-pump CABG involving patients treated with antiplatelet agents. In a retrospective review of patients undergoing on-pump CABG, the beneficial effect of TA on perioperative blood loss and transfusion requirement was less prominent in patients preoperatively treated with clopidogrel. ${ }^{13}$ In contrast, in a prospective study, a single dose of intraoperative TA reduced postoperative bleeding in patients treated with aspirin until the day of on-pump CABG. However, there have been no studies addressing the influence of TA on patients with preoperative DAPT undergoing OPCAB.

In the current trial, TA had a beneficial effect on the amount of pRBC transfusion during the study period. In addition, although it did not reach statistical significance, fewer of the TA group patients required transfusion, even though the overall amount of blood loss during the study period was similar between the groups. The discordance between the reduced transfusion requirement and no difference in the amount of blood loss may be attributed to the following. Firstly, intraoperative use of a cell salvage device appears to mitigate the beneficial influence conferred by TA, especially in terms of the amount of blood loss. Similar results were observed in a previous study addressing the efficacy of TA in conjunction with cell salvage in $\mathrm{OPCAB}$, which excluded patients treated with clopidogrel. ${ }^{26}$ In that study, a significant reduction in blood loss at $4 \mathrm{~h}$ postoperatively was observed (median difference $50 \mathrm{ml}$ ), although there was no difference in total blood loss, as in our study. Secondly, greater FFP requirement in the Control group may have resulted in reduced postoperative bleeding in that group. In a recent meta-analysis, use of TA in OPCAB was associated with a significant reduction in risk of FFP transfusion when PT was used as a transfusion criterion, ${ }^{27}$ as in our study. Thirdly, inaccurate measurement of intraoperative blood loss may also have masked the beneficial influence of TA in terms of blood loss, which is a limitation of our study. TA might have affected the amount of insensible blood loss soaked up by gauzes and tapes, which is often difficult to assess accurately. The absolute amount of insensible blood loss and its difference between the groups may not be considerable. However, because our patients were preoperatively anemic with marginal $\mathrm{Hb}$ levels and little $\mathrm{RBC}$ reserve, the difference in insensible blood loss might have been significant enough to result in less pRBC transfusion in the TA group.

More specifically, TA's beneficial influence on blood loss and transfusion requirement was more prominent during the intraoperative period and for the first $4 \mathrm{~h}$ after surgery, whereas it did not exert any effects over the postoperative $24 \mathrm{~h}$. This is not surprising considering that TA's half-life is $2-4 \mathrm{~h}$ and that it was infused only during the operation, which is in agreement with the results of a recent meta-analysis demonstrating no beneficial influence of TA on midperiod (4-24h) blood loss. ${ }^{27}$ Most critical decisions regarding the transfusion of coagulation factors and/or hemostatic re-exploration are decided within the first $4 \mathrm{~h}$ after surgery. ${ }^{28}$ Thus, the findings that TA had a beneficial influence, especially during the intraoperative and first $4 \mathrm{~h}$ after surgery, even with concomitant use of intraoperative cell salvage device, suggest a potential role as a blood conservation strategy in this subset of patients.

The use of antifibrinolytic agents carries the risk of various thromboembolic events, as well as increasing the early graft occlusion rate in patients undergoing CABG. ${ }^{29}$ TA did not increase the risk of thromboembolic complications or compromise early venous graft patency rate in various studies of both on-pump CABG and OPCAB.$^{29}$ In the current study, any complications related to thromboembolic events or an increase in the rate of perioperative MI were not observed. However, a cumulative warm ischemia-reperfusion injury and systemic inflammatory response elicited by multivessel OPCAB was demonstrated to be associated with a postoperative hypercoagulable state with increased coagulation and fibrinolysis mimicking consumptive coagulopathy. ${ }^{30}$ Thus, we limited the duration of TA infusion to the intraoperative period, although more definite effects of TA on the transfusion requirement could have been observed by extending TA infusion to the postoperative period.

Another limitation is that we did not assess individual platelet responsiveness, which might have confounded the results of the current trial. However, there is currently no generally accepted platelet function assay for assessing the responsiveness to antiplatelet agents that correlates well with blood loss and with enough clinical evidence to support its influence.

In conclusion, intraoperative TA infusion could be safely used as a blood conservation strategy in preoperatively anemic patients who continue DAPT until within 5 days of OPCAB. Its beneficial influence on blood loss and transfusion requirement was mostly confined to the intraoperative period and the 
first $4 \mathrm{~h}$ after operation in relation to the duration of TA infusion and its pharmacokinetics, even with routine use of cell salvage during the operation.

\section{Disclosure}

Name of grant: no fund supported.

\section{References}

1. Hajjar LA, Vincent JL, Galas FR, Nakamura RE, Silva CM, Santos $\mathrm{MH}$, et al. Transfusion requirements after cardiac surgery: The TRACS randomized controlled trial. JAMA 2010; 304: 1559-1567.

2. Scott BH, Seifert FC, Glass PS, Grimson R. Blood use in patients undergoing coronary artery bypass surgery: Impact of cardiopulmonary bypass pump, hematocrit, gender, age, and body weight. Anesth Analg 2003; 97: 958-963.

3. Salisbury AC, Alexander KP, Reid KJ, Masoudi FA, Rathore SS, Wang TY, et al. Incidence, correlates, and outcomes of acute, hospital-acquired anemia in patients with acute myocardial infarction. Circ Cardiovasc Qual Outcomes 2010; 3: 337-346.

4. Kapetanakis EI, Medlam DA, Petro KR, Haile E, Hill PC, Dullum MK, et al. Effect of clopidogrel premedication in off-pump cardiac surgery: Are we forfeiting the benefits of reduced hemorrhagic sequelae? Circulation 2006; 113: 1667-1674.

5. Angiolillo DJ, Ueno M, Goto S. Basic principles of platelet biology and clinical implications. Circ J 2010; 74: 597-607.

6. Sellke FW, Chu LM, Cohn WE. Current state of surgical myocardial revascularization. Circ J 2010; 74: 1031-1037.

7. Song SW, Youn YN, Yi G, Lee S, Yoo KJ. Effects of continuous administration of clopidogrel before off-pump coronary artery bypass grafting in patients with acute coronary syndrome. Circ J 2008; 72: 626-632.

8. Chassot PG, van der Linden P, Zaugg M, Mueller XM, Spahn DR Off-pump coronary artery bypass surgery: Physiology and anaesthetic management. Br J Anaesth 2004; 92: 400-413.

9. Valeri CR, Cassidy G, Pivacek LE, Ragno G, Lieberthal W, Crowley $\mathrm{JP}$, et al. Anemia-induced increase in the bleeding time: Implications for treatment of nonsurgical blood loss. Transfusion 2001; 41: 977 983.

10. Verstraete M. Clinical application of inhibitors of fibrinolysis. Drugs 1985; 29: 236-261.

11. Wei M, Jian K, Guo Z, Wang L, Jiang D, Zhang L, et al. Tranexamic acid reduces postoperative bleeding in off-pump coronary artery bypass grafting. Scand Cardiovasc J 2006; 40: 105-109.

12. Mezzano D, Panes O, Munoz B, Pais E, Tagle R, Gonzalez F, et al. Tranexamic acid inhibits fibrinolysis, shortens the bleeding time and improves platelet function in patients with chronic renal failure. Thromb Haemost 1999; 82: 1250-1254.

13. Senay S, Toraman F, Karabulut H, Alhan C. Efficiency of preoperative tranexamic Acid in coronary bypass surgery: An analysis correlated with preoperative clopidogrel use. Heart Surg Forum 2010; 13: E149-E154.

14. Weber CF, Gorlinger K, Byhahn C, Moritz A, Hanke AA, Zacharowski $\mathrm{K}$, et al. Tranexamic acid partially improves platelet function in patients treated with dual antiplatelet therapy. Eur J Anaesthesiol 2011; 28: 57-62.

15. Vanek T, Jares M, Fajt R, Straka Z, Jirasek K, Kolesar M, et al. Fibrinolytic inhibitors in off-pump coronary surgery: A prospective, ran- domized, double-blind TAP study (tranexamic acid, aprotinin, placebo). Eur J Cardiothorac Surg 2005; 28: 563-568.

16. Shim JK, Choi YS, Oh YJ, Bang SO, Yoo KJ, Kwak YL. Effects of preoperative aspirin and clopidogrel therapy on perioperative blood loss and blood transfusion requirements in patients undergoing offpump coronary artery bypass graft surgery. J Thorac Cardiovasc Surg 2007; 134: 59-64.

17. Nesher N, Alghamdi AA, Singh SK, Sever JY, Christakis GT, Goldman BS, et al. Troponin after cardiac surgery: A predictor or a phenomenon? Ann Thorac Surg 2008; 85: 1348-1354.

18. Molitoris BA, Levin A, Warnock DG, Joannidis M, Mehta RL, Kellum JA, et al. Improving outcomes from acute kidney injury. J Am Soc Nephrol 2007; 18: 1992-1994.

19. Woodman RC, Harker LA. Bleeding complications associated with cardiopulmonary bypass. Blood 1990; 76: 1680-1697.

20. Hartmann M, Sucker C, Boehm O, Koch A, Loer S, Zacharowski K. Effects of cardiac surgery on hemostasis. Transfus Med Rev 2006; 20: $230-241$.

21. Dunning J, Versteegh M, Fabbri A, Pavie A, Kolh P, Lockowandt U, et al. Guideline on antiplatelet and anticoagulation management in cardiac surgery. Eur J Cardiothorac Surg 2008; 34: 73-92.

22. Burger W, Chemnitius JM, Kneissl GD, Rucker G. Low-dose aspirin for secondary cardiovascular prevention: Cardiovascular risks after its perioperative withdrawal versus bleeding risks with its continuation: Review and meta-analysis. J Intern Med 2005; 257: 399-414.

23. Mehta SR, Yusuf S. The Clopidogrel in Unstable angina to prevent Recurrent Events (CURE) trial programme; rationale, design and baseline characteristics including a meta-analysis of the effects of thienopyridines in vascular disease. Eur Heart J 2000; 21: $2033-$ 2041 .

24. Bertrand OF, Larose E, Rodes-Cabau J, Rinfret S, Dery JP, Bagur R, et al. Incidence, range, and clinical effect of hemoglobin changes within 24 hours after transradial coronary stenting. Am J Cardiol 2010; 106: $155-161$.

25. de Haan J, van Oeveren W. Platelets and soluble fibrin promote plasminogen activation causing downregulation of platelet glycoprotein Ib/IX complexes: Protection by aprotinin. Thromb Res 1998; 92: $171-179$.

26. Murphy GJ, Mango E, Lucchetti V, Battaglia F, Catapano D, Rogers $\mathrm{CA}$, et al. A randomized trial of tranexamic acid in combination with cell salvage plus a meta-analysis of randomized trials evaluating tranexamic acid in off-pump coronary artery bypass grafting. J Thorac Cardiovasc Surg 2006; 132: 475-480, 480, e471-e478.

27. Adler Ma SC, Brindle W, Burton G, Gallacher S, Hong FC, Manelius $\mathrm{I}$, et al. Tranexamic acid is associated with less blood transfusion in off-pump coronary artery bypass graft surgery: A systematic review and meta-analysis. J Cardiothorac Vasc Anesth 2011; 25: 26-35.

28. Kirklin J, Barratt-Boyes B. Cardiac surgery. New York: Churchill Livingstone, 1986.

29. Karski J, Djaiani G, Carroll J, Iwanochko M, Seneviratne P, Liu P, et al. Tranexamic acid and early saphenous vein graft patency in conventional coronary artery bypass graft surgery: A prospective randomized controlled clinical trial. J Thorac Cardiovasc Surg 2005; 130: $309-314$.

30. Kon ZN, Brown EN, Grant MC, Ozeki T, Burris NS, Collins MJ, et al. Warm ischemia provokes inflammation and regional hypercoagulability within the heart during off-pump coronary artery bypass: A possible target for serine protease inhibition. Eur J Cardiothorac Surg 2008; 33: 215-221. 